\title{
THE INFLUENCE OF EXTREME EVENTS ON HYDRODYNAMICS AND SALINITIES IN THE WESER ESTUARY IN THE CONTEXT OF CLIMATE IMPACT RESEARCH
}

\author{
Anna C. Zorndt ${ }^{1}$, Torsten Schlurmann ${ }^{1}$ and Iris Grabemann ${ }^{2}$
}

\begin{abstract}
The salinity and its longitudinal distribution in the Weser estuary, Germany, has implications for water management as the estuarine water is needed, e.g., for irrigation of the agricultural used hinterlands and as industrial water and because of its intrusion into groundwater. Generally, the salinity distribution is determined by tidal dynamics, river runoff from the catchment area, amount of intruding seawater from the German Bight (North Sea) as well as by the salinities of both river and seawater. Anthropogenic climate change may have an impact on the estuarine dynamics and, thus, on the salinity distribution. This study focuses on the impact of storm surges. A semi-implicit Eulerian-Lagrangian finite element model was used to simulate hydrodynamics and salinities in the estuary. By comparing simulated and observed data of two past storm surges it is shown that the model is well capable of reproducing estuarine dynamics. Possible future changes due to climate change are investigated for three scenario- based storm surges; two of them represent future storm conditions and one specifies reference (today's) conditions for comparison. These storm surges were simulated using boundary conditions from water level simulations with a hydrodynamic model for the North Sea together with the respective meteorological forcing. It can be shown that during storm tides, isohalines penetrate more than $30 \mathrm{~km}$ further upstream than during normal conditions. For the most severe scenario-based storm surge, this leads to a salinity increase of up to 30 psu within the mixing zone during the highest storm tide.

Keywords: climate impact research; estuary modeling; salinity intrusion; storm events; Weser
\end{abstract}

\section{INTRODUCTION}

The study presented here is part of a research co-operation in Lower Saxony (Germany) for assessing possible effects of anthropogenic climate change on a regional basis (Niemeyer and Kaiser 2012) ${ }^{3}$. As part of this framework, we focus on studying the impact of climate change on hydrodynamics and salinity intrusion in the Weser estuary. The estuary is located in Northern Germany, opening into the tidelands of the German Bight (North Sea). The low-lying hinterland of the estuary is protected against storm surges and river floods by dikes and flood barriers. Near the seaward border of the estuary, the average tidal range is $2.8 \mathrm{~m}$ with an almost constant salinity of approx. $32 \mathrm{psu}$. The natural conditions of the estuary are substantially altered due to deepening and other river training measures so that by propagation through the estuary, so that the tidal range increases to $4.0 \mathrm{~m}$ at the weir in Bremen which constitutes meso- to macrotidal conditions. The long-term average of the freshwater discharge is $326 \mathrm{~m}^{3} \mathrm{~s}^{-1}$. During average conditions, the interface between salt- and freshwater is located approx. $60 \mathrm{~km}$ from the weir. Due to the need for the estuarine water e.g. as industrial water and irrigation, the longitudinal salinity distribution can play an important role in water management.

To analyse impacts of storm surges on the salinity intrusion in the Weser estuary, a set of storm surges with differing intensities was simulated. This set includes two past storm surges to establish today's conditions and three "scenario" surges to estimate possible future changes in the salinity intrusion due to expected anthropogenic climate change. Two of the scenario storm surges reflect possible future conditions and one of them reflects corresponding reference conditions for comparison.

This paper presents some preliminary results and is outlined as follows: First, the methods are shown which comprehend the employed semi-implicit Eulerian-Lagrangian finite element model and its set-up. It follows a description of the boundary condition generation for the simulation of past and scenario storm surges. Finally, results are presented with a focus on the influence of storm events on the salinity distribution in the estuary. The paper is closed with a summary and discussion of the results as well as a short outlook on the following studies undertaken in the project framework presented here.

\section{METHODS}

3D baroclinic numerical modeling with the semi-implicit Eulerian-Lagrangian finite-element model

For the simulation of hydrodynamics and salinitiy in the estuary, a 3D baroclinic circulation model (SELFE) was employed. It was implemented by Zhang and Baptista (2008) on unstructured grids which is an important requirement for simulating complex bathymetries without nesting. The current program version is parallelized and good scalability and efficiency were achieved (Zhang et al. 2011). The model solves the 3D shallow water equations with hydrostatic assumption and Boussinesq approximation and transport equations for salinity and temperature.

\footnotetext{
${ }^{1}$ Franzius-Institute for Hydraulic, Waterways and Coastal Engineering, Leibniz Universität Hannover, Nienburger Str. 4, 30167 Hannover, Germany

2 Helmholtz-Zentrum Geesthacht, Max-Planck-Str. 1, 21502 Geesthacht, Germany

${ }^{3}$ KLIFF, for further details, please refer to www.kliff-niedersachsen.de
} 


\section{Model domain}

The bathymetry is based on single- and multi beam echo soundings as well as highly resolved LIDAR data which were provided by the Waterways and Shipping Administration of the Federal Government of Germany. The horizontal and vertical accuracy of this data is usually in the order of centimeters. From this data basis of about $400 \mathrm{M}$. points, a bathymetry was constructed, hereby preferring data sets from the years 2008 and 2009.

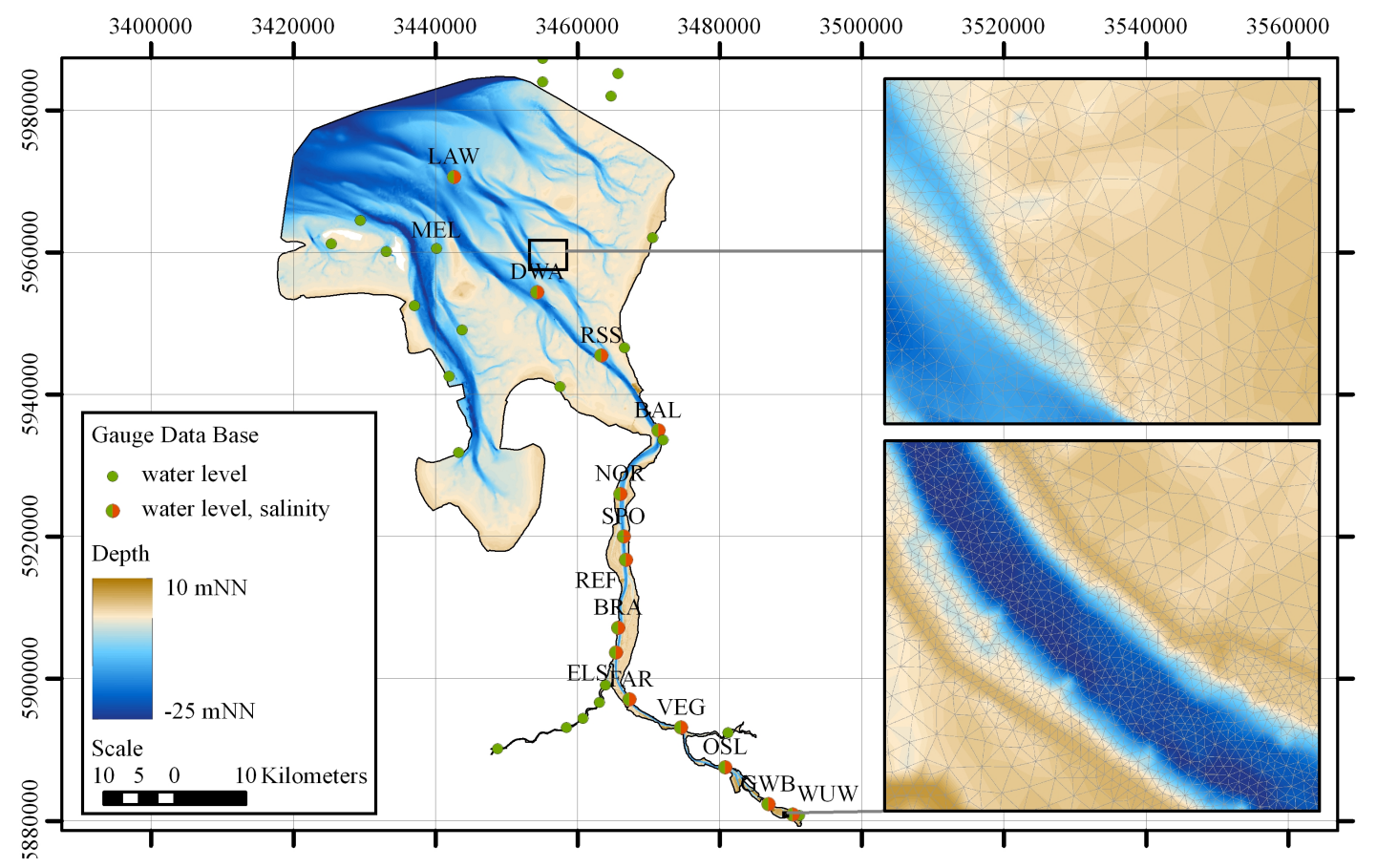

Figure 1. Model domain of the Weser estuary, details of triangular mesh and gauge data base available for model calibration.

The model domain ranges from the German Bight in the North to the weir in Bremen approximately $100 \mathrm{~km}$ south of the Northern boundary (see Fig. 1). The open boundary to the German Bight was set as far outside as possible to achieve almost constant salinity at the boundary without interfering with the adjacent Elbe Estuary and the East Friesian Coastline. The tributaries Hunte, Lesum and Wümme/Hamme located in the inner estuary are partially included. This constitutes a simplification in case of storm surge modeling, as the tributaries are protected with flood barriers which are closed for some hours during high water in case of storm surges. As the focus of this presentation is the salinity distribution in the outer estuary and beginning of the channel, the effect of closing flood barriers on the deformation of the tidal wave can be neglected. In order to simulate storm surges which lead to wetting of floodplains and retention areas, the outer closed boundary to the inland has to be chosen as the flood protection dike line.

A meshing approach based on the meshing tool Triangle (Shewchuk 1996) was employed, in which adopted Matlab routines from Bilgili et al. (2006) were used to generate input files for Triangle and to import Triangle output back to Matlab. For accurate modeling the propagation of a flood wave, it is necessary for the mesh to include small local features such as summer dike lines. Therefore in a first step, polygones were generated in a geo-information system software representing both the aforementioned coastline and features to be incorporated in the mesh, such as element edges. Also, zones within the domain were defined and assigned minimum element areas for the initial Triangle mesh. The polygones were imported into Matlab and an initial Triangle mesh was produced, considering besides the aforementioned polygons also a minimum inner element angle of $\alpha=30^{\circ}$. For a second refinement, the areas of all triangles were calculated and evaluated for Bilgili's criterion $A \leq \frac{h}{\text { Deltah }} \alpha$. The violating triangles were refined with a second Triangle run. The resulting mesh consists of elements with edge lengths ranging from several hundreds of meters in the outer parts of the estuary to $10 \mathrm{~m}$ in the inner parts of the estuary. 


\section{Boundary conditions}

Past storm surges were modeled with boundary and initial conditions generated by gauge measurements. The open boundary to the German Bight was forced with water levels generated from gauge LAW, while river runoff at Inschede, a station about $30 \mathrm{~km}$ upstream, was used to construct boundary conditions for the weir in Bremen as well as the open boundaries of the tributaries Hunte, Wümme and Hamme. A spatially uniform wind forcing was set up over the domain, which was generated based on measurements of two stations near the mouth of the estuary. Besides, the open boundaries were forced with constant salinity of 32 psu at the open boundary to the German Bight and 0.5 psu at the influx boundaries of the weir and the tributaries. The model was started 14 days before the actual storm surge. To achieve a realistic initial salinity distribution at the time of simulation start to reduce pre-run time, salinity measurements were used (locations depicted in Fig. 1). The measured salinity was averaged over the period of $\mathrm{M}_{2}$ at each gauge and then spatially interpolated to the grid.

Scenario storm surges were modeled based on boundary conditions from transient water level simulations for the North Sea for different future climate projections (Gaslikova et al. 2012). The hydrodynamic model for the North Sea with a grid resolution of about $12.8 \mathrm{~km}$ x $12.8 \mathrm{~km}$ was forced with regionalized atmosheric data (regional climate model COSMO-CLM, Rockel and Geyer 2008) from global reference simualtions for 1961-2000 and climate projections for 2001-2100 (general circulation model ECHAM5/MPI-OM, Jungclaus et al. 2006). This set of climate projections reflects two IPCC scenarios of future emissions. From the water level simulations, three severe storm surges with high peak water levels were chosen to further simulate storm surge impacts on the salinity in the Weser estuary. One event is from the reference simulation (C20_1) and two events are from the future projections for A1B_1 and B1_1 (for more details see Gaslikova et al. 2012). The boundary conditions were generated from model results of three North Sea grid points in the vicinity of the Weser open boundary.

The storm event from the reference period (in the following referred to as $\mathrm{Storm}_{\mathrm{C} 20_{-} 1}$ ) has a peak water level of $3.8 \mathrm{mNN}$. This water level corresponds to a return period of 35 years based on the years 1961 to $2000^{4}$. The return period for this peak water level would decrease to about the half (17-18 years) in the climate projection (scenario) period 2001-2100. The scenario storm events (in the following referred to as Storm $_{\mathrm{A} 1 \mathrm{~B}_{-} 1}$ and $\mathrm{Storm}_{\mathrm{B} 1_{1} 1}$ with peak water levels of $4.7 \mathrm{mNN}$ and $4.8 \mathrm{mNN}$ have return periods of 480 years (95\% confidence interval based on a bootstrapping approach: 130 to $>1000$ years) and 205 years (confidence interval: 80 to $>1000$ years), based on the respective scenario periods 2001 to 2100 .

From the respective wind fields, the atmospheric boundary conditions were constructed. As no respective scenario-based projections for the river runoff are available yet, a mean runoff was imposed at the open boundary at the weir. The initial salinity distribution was generated to fit the mean river discharge. Salinity and temperature boundary condtitions were chosen in the same manner as for the past storm surges.

\section{Model set-up and calibration}

A broad database of field measurements for calibration is available throughout the year, consisting of gauges for water level $w l$ and salinity $s$ (see Fig. 1).

The mesh was calibrated for the period of April 2009. Parameter studies were carried out to find the best set-up for the calculation regarding timestep, vertical resolution, scalar transport advection and turbulence closure schemes (not shown here). The parameters finally selected were a timestep of $\Delta t=$ $40 \mathrm{~s}$ and $n_{s}=25$ vertical s-levels with a skewness of $\theta_{f}=5$ for concentrating the levels on the bottom and surface of the vertical domain $\left(\theta_{b}=1\right)$. The $k-\omega$ scheme was used for turbulence closure.

The model set-up was used to simulate storm surges of the recent past in which the availability of digital observation data was sufficient to comprehensively assess the model's skill of reproducing hydrodynamics and salinity during these events. The results of storms Britta from Nov 1 st 2006 and Tilo from Nov 9th 2007 are presented here with the focus of comparing observed and simulated values (Fig. 2 and 3$)^{5}$.

The agreement between observed and simulated water levels during both storm events is very well except for a slight overestimation of the low tides during the storm event.

The ability of the model to reproduce the observed salinity is well before and during the storm events.

\footnotetext{
${ }^{4}$ The return values were calculated by fitting a generalized extreme value (GEV) distribution to the time series of annual maximum water levels.

${ }^{5}$ Water levels relate to the German reference datum NN, approximately corresponding to mean sea level (MSL)
} 


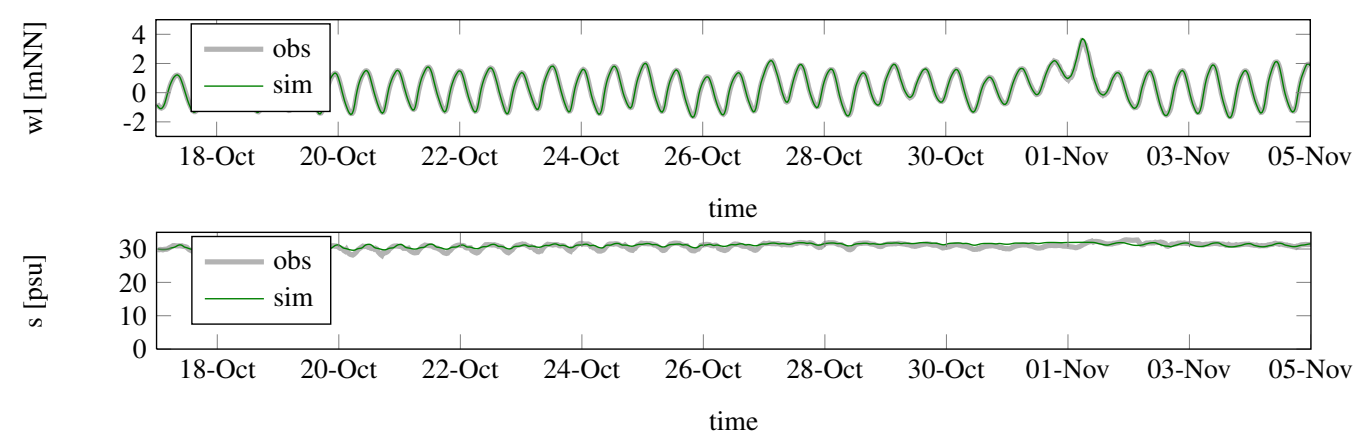

(a) Gauge LAW
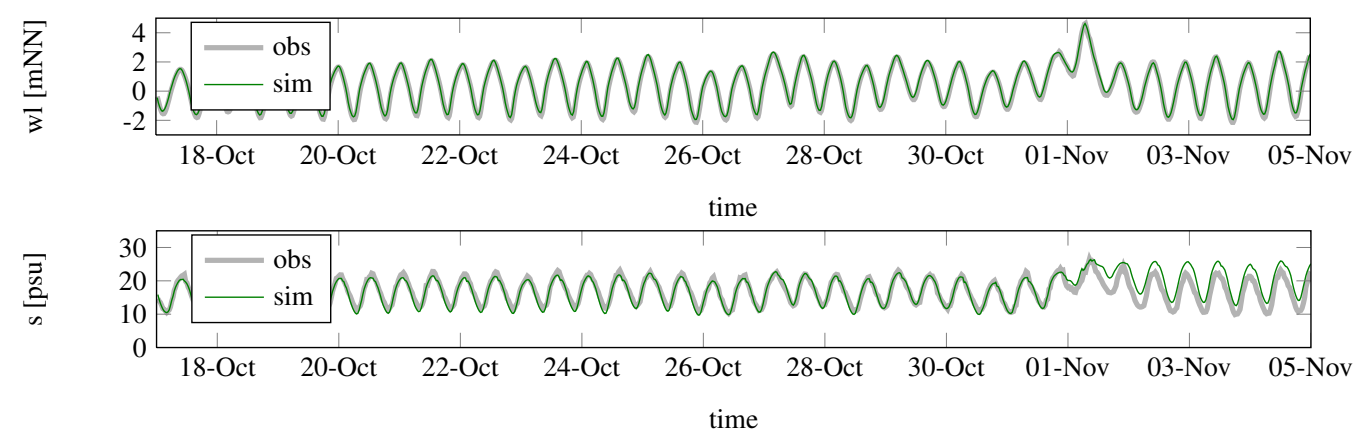

(b) Gauge BAL

Figure 2. Simulated and observed water level (top) and salinity (bottom) during storm Britta in 2006.

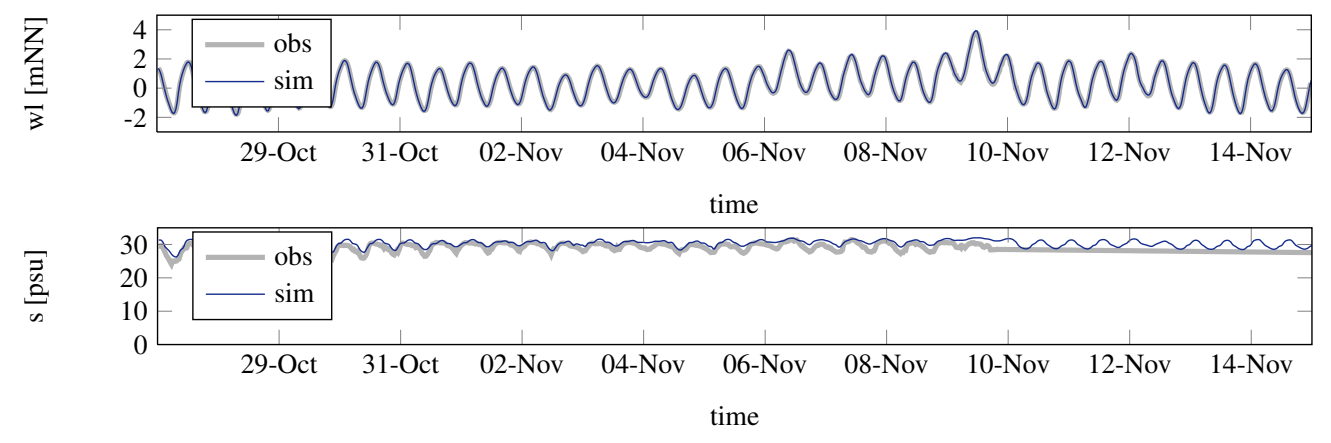

(a) Gauge LAW
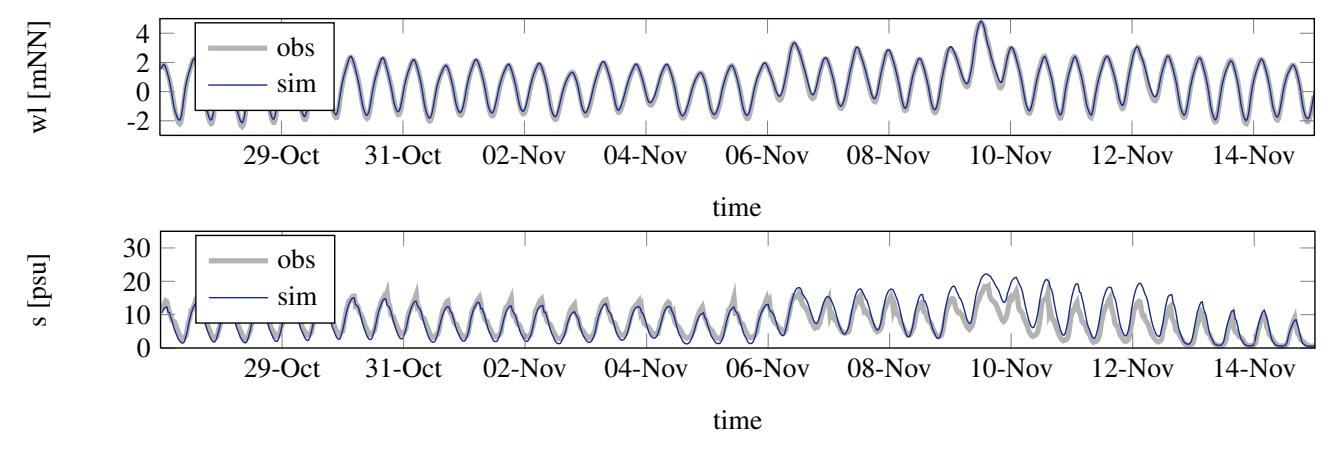

(b) Gauge BAL

Figure 3. Simulated and observed water level (top) and salinity (bottom) during storm Tilo in 2007. 
Following the rise of the salinity during the storm event, however, the observed salinity decreases sooner to the level before the storm surge, while the model overestimates salinity magnitude. Two root causes are believed to contribute to this effect: The constant forcing at the open boundary of 32 psu leads to an overintrusion of comparatively high salinity even during low tide which is enforced by the overestimation of simulated water levels at low tide so that washout of salinity is hindered. The overestimation is less pronounced during storm event Tilo, as it coincides with a strong increase of river runoff.
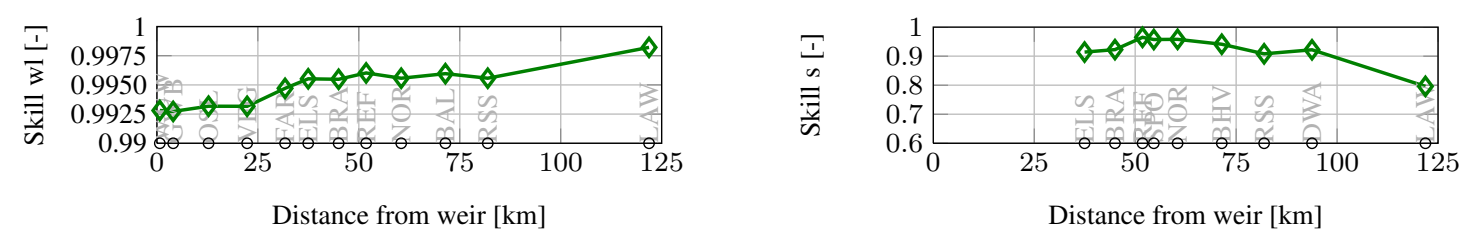

(a) Storm Britta
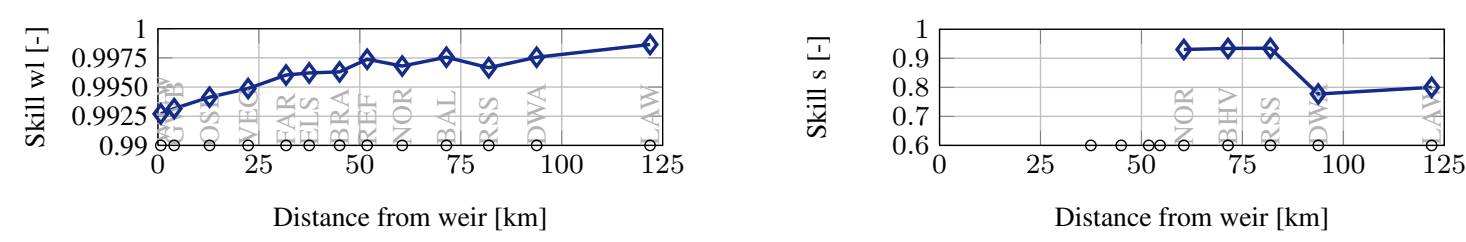

(b) Storm Tilo

Figure 4. Model skill for predicting water level (left) and salinity (right) for all available gauges along the main channel.

A dimensionless model skill (Willmott 1981) has been computed for each gauge to assess the ability of the model to predict water surface elevation and salinity for all available gauges in vicinity to the main channel. For storm event Britta in 2006, 9 stations measuring salinities with average values greater 1 psu, as well as 12 water level gauges are available (Fig. 4 a). The average model skill of predicting water level for all available stations is 0.995 for the whole simulation period. The salinity is predicted with an average skill of 0.985 . During storm event Tilo (Fig. 4 b), the average model skill of predicting water level for 13 available gauges is 0.996 . The skill of predicting salinity for 5 available stations with salinity higher than $1 \mathrm{psu}$ is 0.875 . Generally, the model skill for predicting water level is higher close to the open boundary to the German Bight, as it is forced by a water level time series generated by gauges. The salinity however shows lower skill values here due to the constant salinity forced at the boundary (see above).

\section{Quantification of the impact of storm surges on salinity}

One way of investigating the impact of storm events on the salinity distribution is to compare the salinity distribution during a storm event to similar periods in which no surge was present. However, except for the impact of the storm surge, the salinity distribution depends on the tide, river discharge, mean water level variations and the salinity of sea water and river discharge itself (Grabemann et al. 1983). This set of dominating parameters obscures a detailed investigation of the influence of storm surges based on comparisons of measured data. In this contribution, an alternative approach was adopted in which no-storm simulations are carried out which are defined as follows: The simulations of the storm events were repeated under modified boundary conditions from which the storm event's impact, namely surge and wind increase during the storm, were extracted. In case of the past storm surges, a harmonic analyses of the water level time series at the boundary was conducted to distinguish between astronomical tide and meteorological residuum. For the scenario storm surges, water level simulations of the North Sea forced only by the astronomical tide were available. The storm event was then defined as the time during which the meteorological residuum was significantly higher than $0.5 \mathrm{~m}$. This part of the meteorological residuum was extracted from the boundary condition so that the water level would only

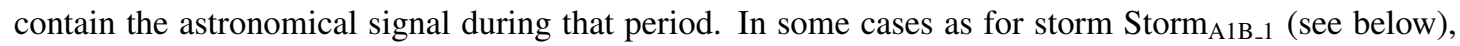
the storm incluedes a series of directly following events. Instead of the measured or simulated wind, an average wind was forced on the model for the no-storm runs. 


\section{RESULTS}

The propagation of the simulated storm tides through the estuary is shown in Fig. 5 and 6 for seven positions. The first is located close to the weir, the others follow along the main channel with distances of $20 \mathrm{~km}$. Water level time series are shown for storm and no-storm simulations (blue and red lines). The differences between both (light blue) are depicted as residua but it should be stressed that they not only contain the influence of the meteorological residuum but also interactions between astronomical tide and the latter.

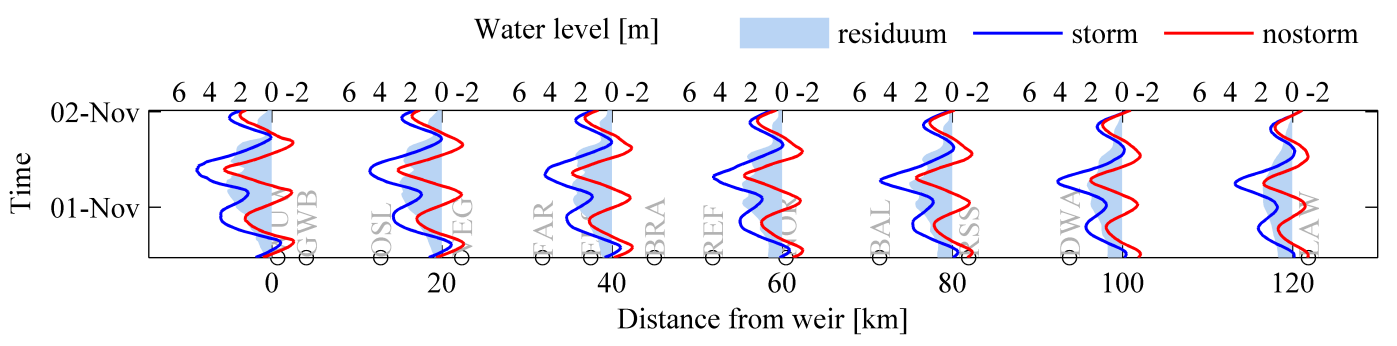

(a) Britta 2006

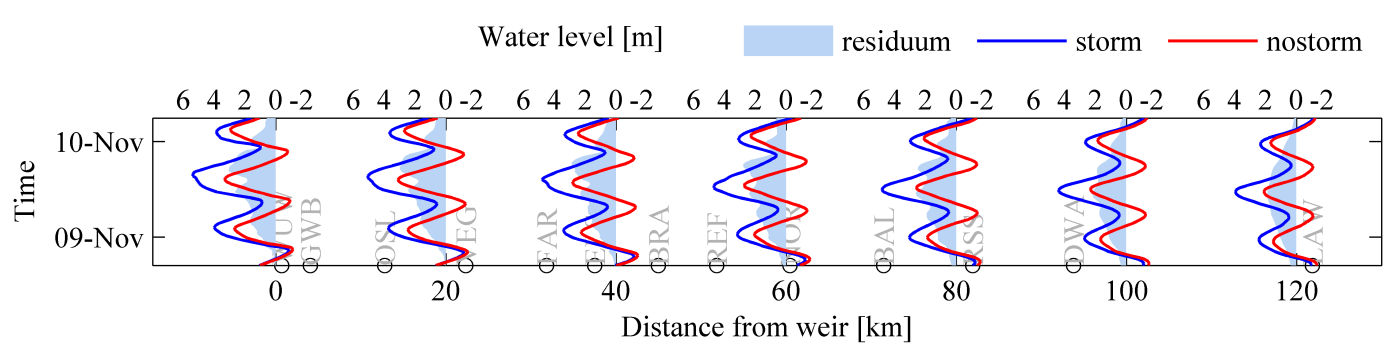

(b) Tilo 2007

Figure 5. Simulated water surface elevation during storm and no-storm simulations and meteorological residua over time and distance from weir for past storm surges.

Severe storm surge events typically last for more than the period $\mathrm{M}_{2}$ so that they consist of two or more succeeding high tides with significantly increased peaks in comparison to the astronomical tide. Such succeeding enhanced high tides are defined as one event if the corresponding meteorological residuum (surge height) remains greater than $0.5 \mathrm{~m}$ without interruption. A sequence of such events only interrupted by one to three tides without enhanced surge height is here referred to as chain event (cmp. Fig. $6 \mathrm{~b}$ and $\mathrm{c})$.

The evolution of the longitudinal depth-averaged salinity during storm surge Tilo is presented in Fig. 7. The salinity distributions of no-storm (Fig. 7 a) and storm simulations (Fig. 7 b) are shown by means of contour lines depicting isohalines of constant salinity over time and distance from the tidal weir in Bremen. Fig. 8 b depicts the differences between the salinity distributions of storm- and no-storm simulations in the same manner. For all other simulated storm surges, only the salinity differences are presented (Fig. 8 a, 9 a-c).

\section{Past storm surges}

During the storm Britta on Nov 1st 2006, a severe surge was generated in the North Sea. In the outer Weser estuary, the simulations show a surge set-up with a duration of 1.5 days and a maximum of $1.9 \mathrm{~m}$ as well as a high water level of $3.7 \mathrm{mNN}$. After propagation of the tidal wave through the estuary, the peak water level is $4.7 \mathrm{mNN}$ with a maximum residuum between storm and no-storm simulation of $2.8 \mathrm{~m}$ (Fig. 5 a).

Tilo, the second past storm surge presented here, occured in Nov 9th 2007 and was preceded by a smaller event three days before (not shown here). The main difference to event Britta is that Tilo was accompanied by a high discharge of $1000 \mathrm{~m}^{3} \mathrm{~s}^{-1}$ which corresponds to the long-term mean of the annual maxima (Spekker 2008). The simulations show a surge duration of 1.4 days and a maximum surge height of $1.9 \mathrm{~m}$ in the outer estuary which almost coincides with the second high tide so that a peak water level 
Water level [m] residuum

- storm nostorm

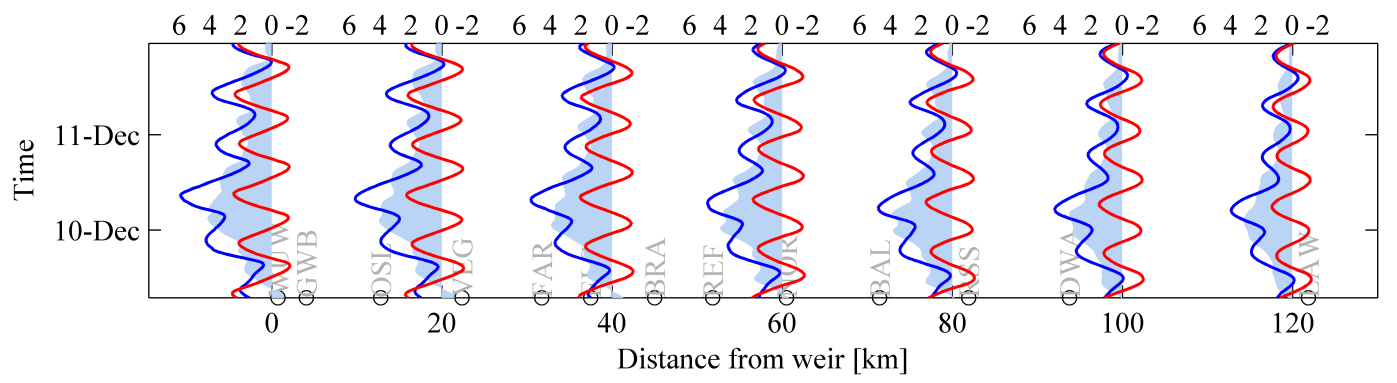

(a) Storm ${ }_{\text {C20_1 }}$

Water level $[\mathrm{m}] \quad$ residuum $\quad$ storm nostorm

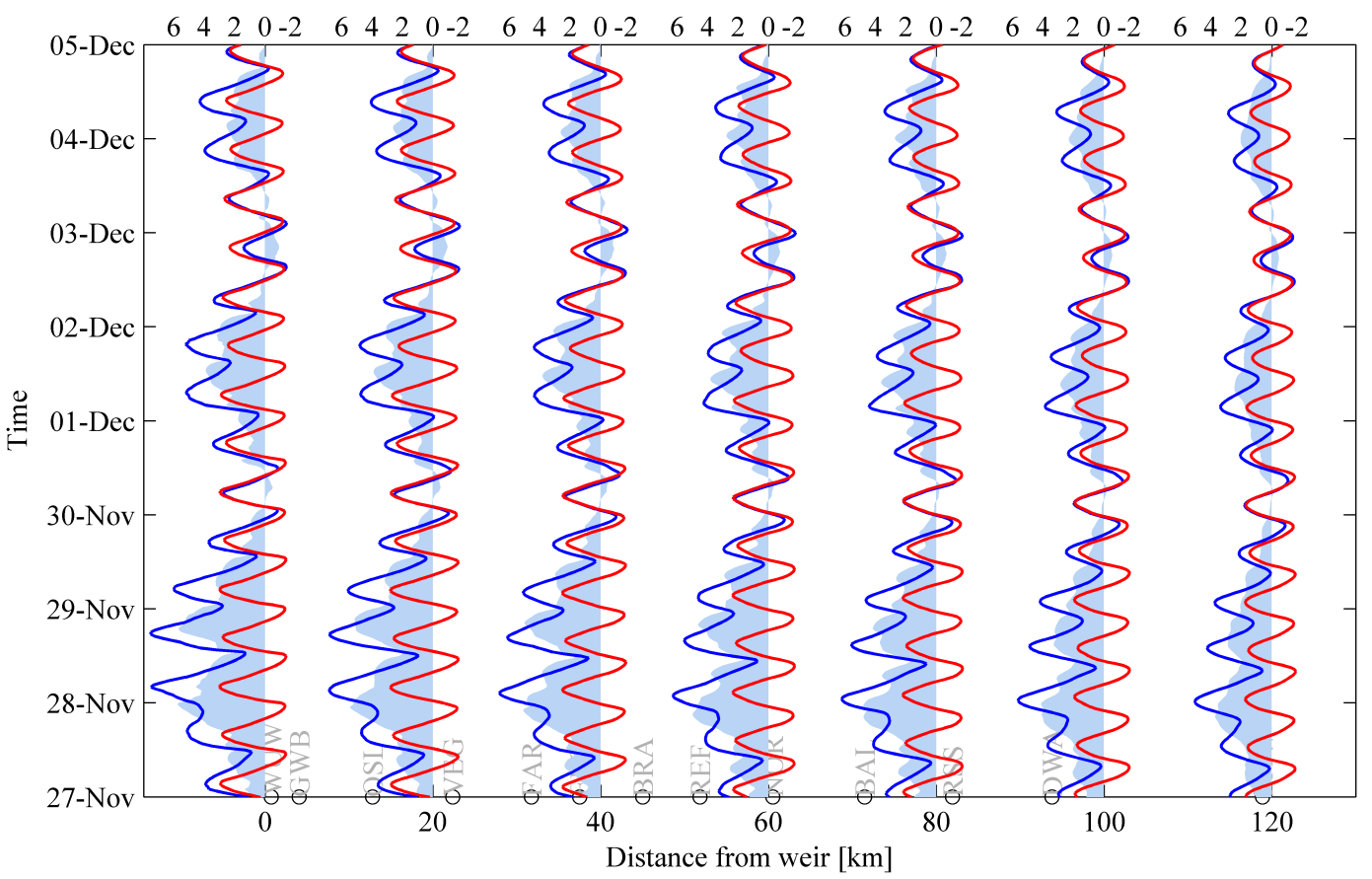

(b) Storm A1B $11_{1}$

Water level $[\mathrm{m}] \quad$ residuum $\quad$ storm nostorm

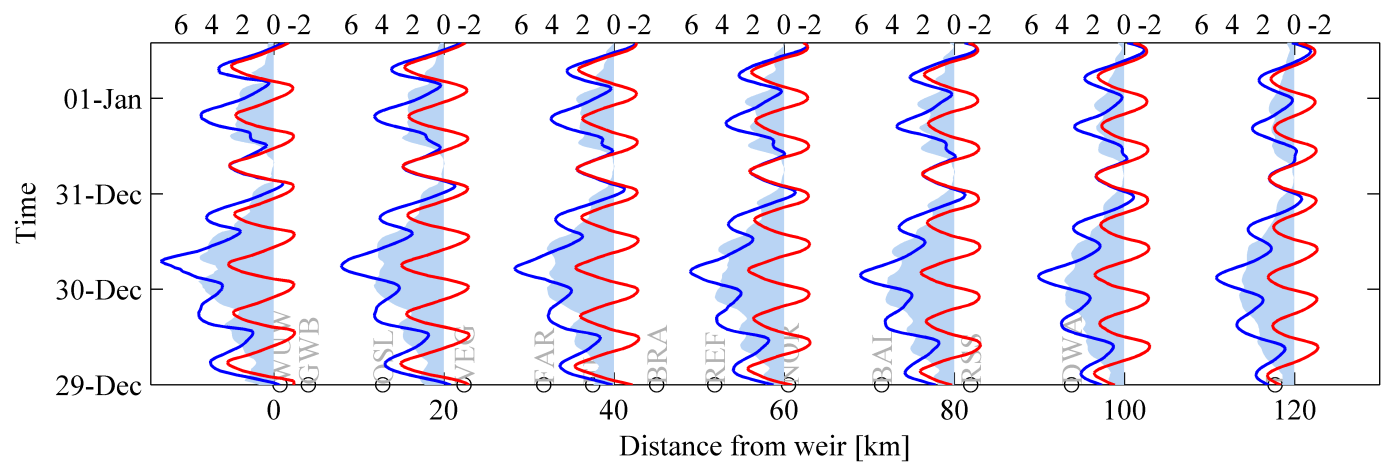

(c) Storm B1_1

Figure 6. Simulated water surface elevation during storm and no-storm simulations and meteorological residua over time and distance from weir for scenario storm surges. 


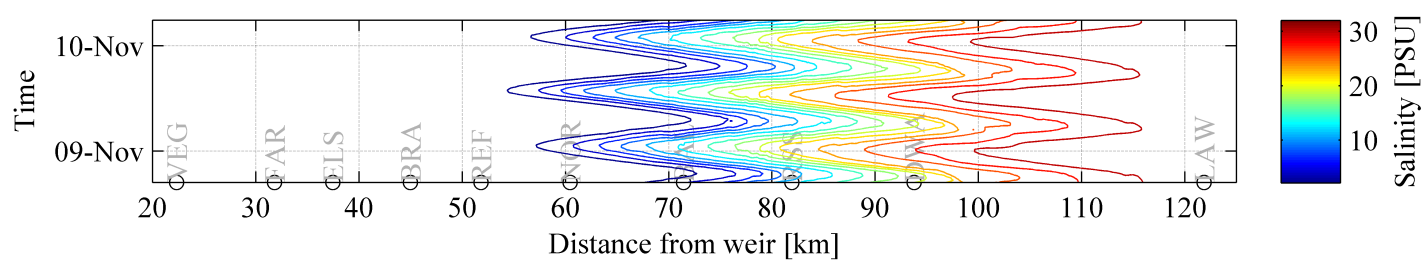

(a) No-Storm simulation

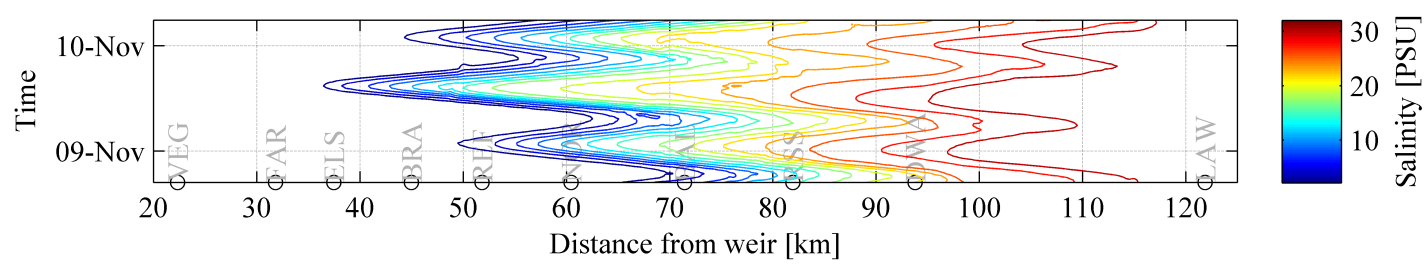

(b) Storm simulation

Figure 7. Depth-averaged salinity isohalines over time and distance from weir for storm surge Tilo.

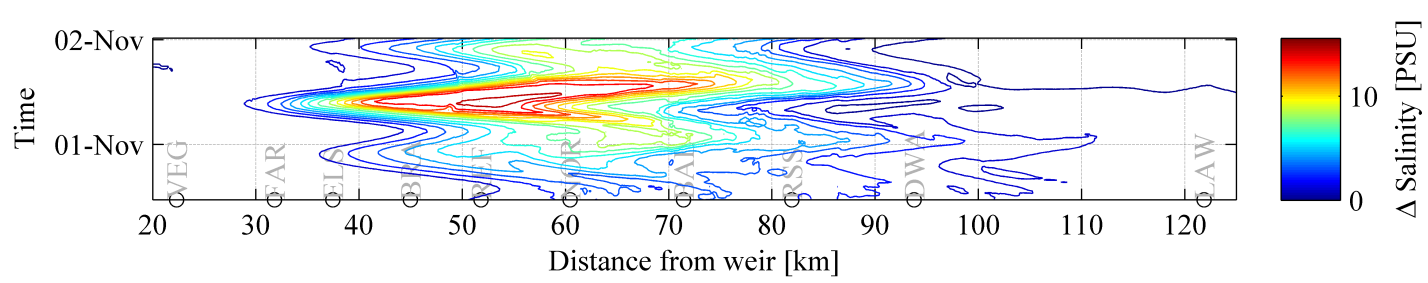

(a) Storm Britta

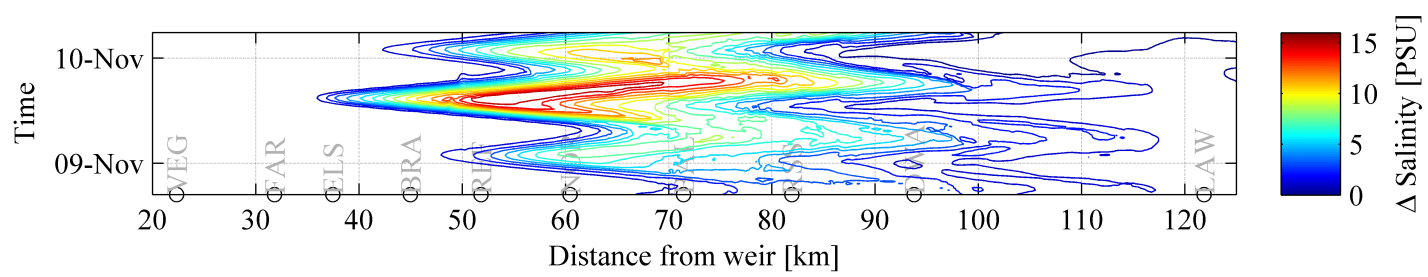

(b) Storm Tilo

Figure 8. Differences of depth-averaged salinities of storm- and no-storm simulations over time and distance from weir for past storm surges.

of $3.9 \mathrm{mNN}$ is reached. In the inner estuary, an amplification of peak water level and surge height to $5.1 \mathrm{mNN}$ and $3.0 \mathrm{~m}$ can be seen in the simulations.

Furthermore, the simulations show that the salinity intrudes much further into the estuary during the two storm surges than during the corresponding no-storm simulations (Fig.8). In the no-storm simulation of storm Tilo (Fig. 7a), the vertically averaged $10 \mathrm{psu}$ isohaline reaches a position of $64 \mathrm{~km}$ from the weir during high tide. In the storm simulation, this isohaline is displaced upstream to a location of $44 \mathrm{~km}$ from the weir during the second increased storm tide (Fig. 7b). For storm Britta, the 10 psu isohaline intrudes to a location of $55 \mathrm{~km}$ from the weir during the no-storm, and to $37 \mathrm{~km}$ during the storm simulation (not shown here). This difference is caused by the low river discharge during the event (see above). The maximum displacement of the $10 \mathrm{psu}$ isohaline is $25 \mathrm{~km}$ for storm surge Tilo and $20 \mathrm{~km}$ for storm surge Britta. Similar displacements are found for the other isohalines. The evolution of the salinity differences in Fig. 8 shows that this leads to a salinity increase of more than 10 psu in a river reach of approx. $25 \mathrm{~km}$ length during the peak high tide (Fig. 8). 


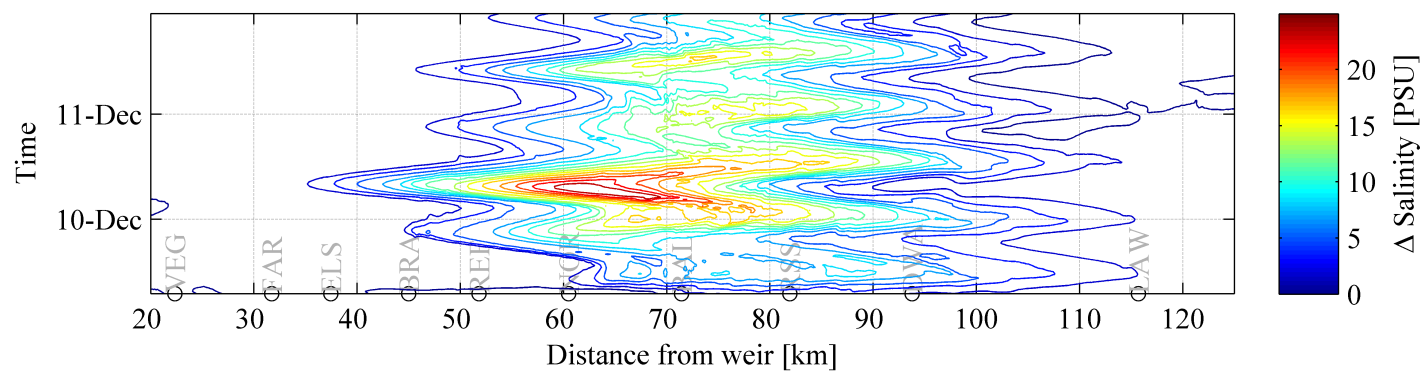

(a) Storm C20_1 $_{1}$

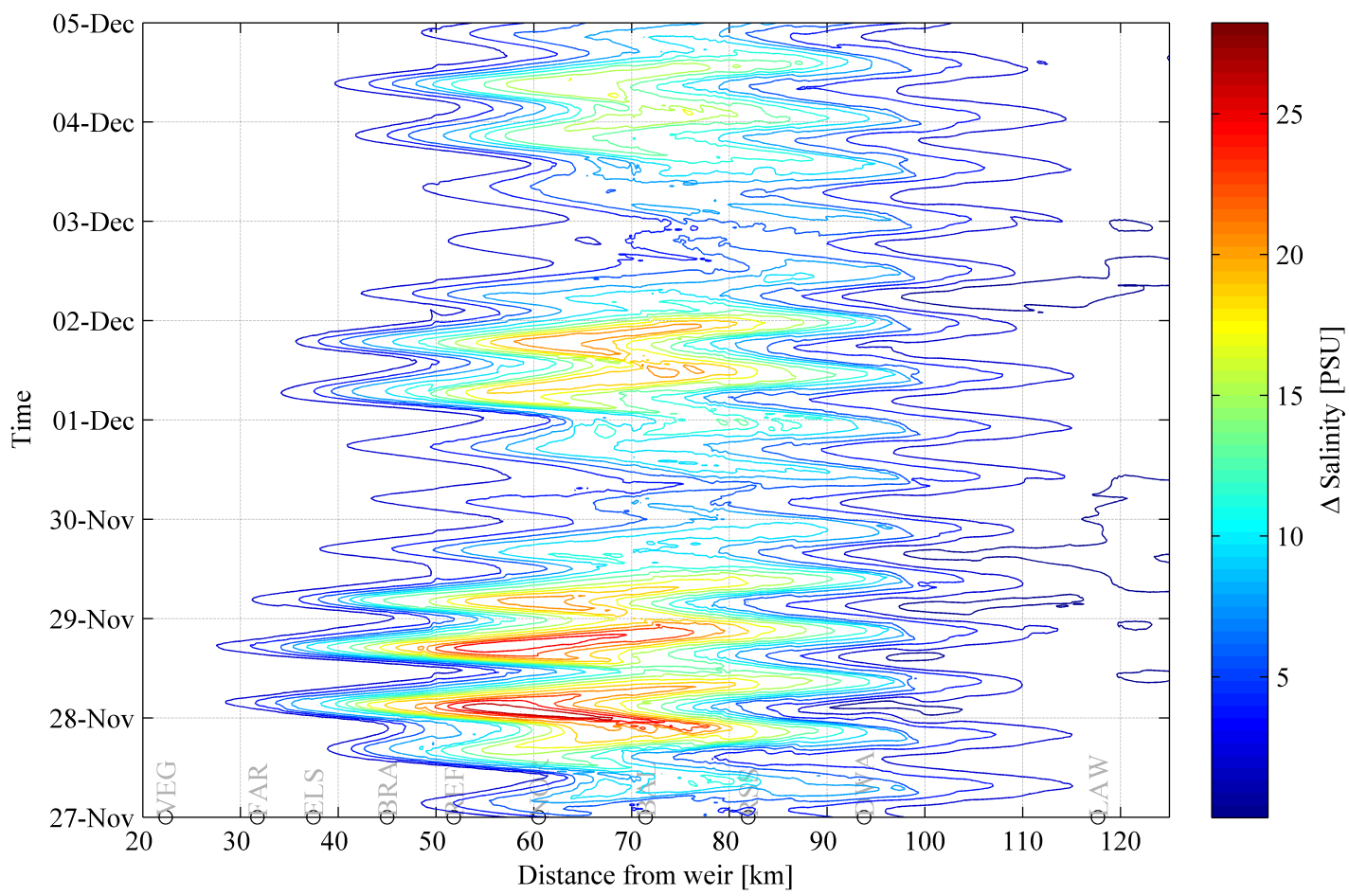

(b) Storm A1B_1 $_{\text {_t }}$



(c) Storm B1_1 $_{1}$

Figure 9. Differences of depth-averaged salinities of storm- and no-storm simulations over time and distance from weir for scenario storm surges. 


\section{Scenario storm surges}

The storm chosen from the reference climate, Storm $_{\mathrm{C}_{20} 1}$ presented in Fig. 6 a, shows a maximum surge height of $3.1 \mathrm{~m}$ and a duration of $2.3 \mathrm{~d}$. This leads to four consecutive high tides of which the second one has the highest peak value of $4.0 \mathrm{mNN}$. When the storm tides propagate through the estuary, the peak water level increases to $5.6 \mathrm{mNN}$.

Scenario storms Storm $\mathrm{A1B}_{\_} 1$ and Storm ${ }_{\mathrm{B} 1 \_1}$ shown in Fig. $6 \mathrm{~b}$ and c, are chain events with decreasing surge height and duration. The first events show surge maxima of $3.7 \mathrm{~m}$ and $3.6 \mathrm{~m}$ in the outer estuary. The main difference between the two is the particularly long surge duration of $3.5 \mathrm{~d}$ during Storm $_{\mathrm{A}_{1} \mathrm{~B}_{-} 1}$ which results in six consecutively increased high tides. The highest tide in the outer estuary of $5.0 \mathrm{mNN}$ is followed by a second comparatively high tide of $4.2 \mathrm{mNN}$. Due to the deformation of the tidal wave in the estuary, the second high tide increases so that both have peak values of $6.8 \mathrm{mNN}$ at the location $20 \mathrm{~km}$ from the weir (Fig. 6 c). The second and third events of both storms are less strong with values in the same range as those of the past and reference climate storm events.

For Storm A1B_1 $_{-1}$ and Storm $_{\mathrm{B}_{1} 1}$, a high salinity increase can be observed whole maximum comes to pass in the first chain event (Fig. $9 \mathrm{~b}$ and c). The maximum displacements of the 10 psu isohalines are $34 \mathrm{~km}$ and $36 \mathrm{~km}$, respectively. In a river reach of approx. $40 \mathrm{~km}$ length, a salinity increase of greater $10 \mathrm{psu}$ is observed during the storms, with maximum set-ups of up to $30 \mathrm{psu}$.

\section{Comparison and discussion}

An overview over the storm surges presented in this study is given in Table 1 which depicts surge duration as well as simulated peak water level and maximum surge. The values are given at a location in the outer estuary located $120 \mathrm{~km}$ and one in the inner estuary located $20 \mathrm{~km}$ from the weir. Please note that the maximum surge does not necessarily coincide with the astronomical high water. To quantify the effect of the storm surge on the vertically integrated longitudinal salinity distribution, the table also depicts the maximum displacement of the $10 \mathrm{psu}$ isohaline derived by analysis of the isohaline locations during storm- and no-storm simulations.

\begin{tabular}{|c|c|c|c|c|c|c|c|}
\hline \multirow[b]{2}{*}{ Name } & \multirow[b]{2}{*}{$\begin{array}{l}\text { Event } \\
\text { no. }\end{array}$} & \multirow[b]{2}{*}{$\begin{array}{l}\text { Surge } \\
\text { duration }\end{array}$} & \multicolumn{2}{|c|}{ Outer estuary } & \multicolumn{2}{|c|}{ Inner estuary } & \multirow{2}{*}{$\begin{array}{l}\text { Salinity } \\
10 \mathrm{psu} \\
\text { isoh. } \\
\text { displ. }\end{array}$} \\
\hline & & & Surge max. & Peak wl & Surge max. & Peak wl & \\
\hline Britta, Nov 1st 2006 & $T$ & $1.5 \mathrm{~d}$ & $1.9 \mathrm{~m}$ & $3.7 \mathrm{mNN}$ & $2.8 \mathrm{~m}$ & $4.7 \mathrm{mNN}$ & $20 \mathrm{~km}$ \\
\hline Tilo, Nov 9th 2007 & I & $1.4 \mathrm{~d}$ & $1.9 \mathrm{~m}$ & $3.9 \mathrm{mNN}$ & $3.0 \mathrm{~m}$ & $5.1 \mathrm{mNN}$ & $25 \mathrm{~km}$ \\
\hline Storm $_{\mathrm{C} 20 \_1}$ & I & $2.3 \mathrm{~d}$ & $3.1 \mathrm{~m}$ & $4.0 \mathrm{mNN}$ & $4.1 \mathrm{~m}$ & $5.6 \mathrm{mNN}$ & $22 \mathrm{~km}$ \\
\hline \multirow[t]{3}{*}{ Storm A1B_1 } & I & $3.5 \mathrm{~d}$ & $3.7 \mathrm{~m}$ & $5.0 \mathrm{mNN}$ & $5.5 \mathrm{~m}$ & $6.8 \mathrm{mNN}$ & 34 km \\
\hline & II & $1.8 \mathrm{~d}$ & $2.4 \mathrm{~m}$ & $3.4 \mathrm{mNN}$ & $3.9 \mathrm{~m}$ & $4.8 \mathrm{mNN}$ & $27 \mathrm{~km}$ \\
\hline & III & $1.2 \mathrm{~d}$ & $2.0 \mathrm{~m}$ & $2.8 \mathrm{mNN}$ & $2.6 \mathrm{~m}$ & $4.1 \mathrm{mNN}$ & 19 km \\
\hline \multirow[t]{2}{*}{ Storm $_{B 1 \_1}$} & I & $2.1 \mathrm{~d}$ & $3.6 \mathrm{~m}$ & $5.0 \mathrm{mNN}$ & $4.5 \mathrm{~m}$ & $6.7 \mathrm{mNN}$ & 36 km \\
\hline & II & $0.7 \mathrm{~d}$ & $1.6 \mathrm{~m}$ & $2.7 \mathrm{mNN}$ & $2.7 \mathrm{~m}$ & $4.5 \mathrm{mNN}$ & 24 km \\
\hline
\end{tabular}

Generally, it can be concluded that the salinity intrusion increases with the intensity of the storm. However, the results show that the evolution of the storm surges is complex and the associated salinity intrusion depends on a multitude of factors. As an example, a comparison of the events Britta, Tilo and Storm $_{\mathrm{C} 20_{-} 1}$ reveals that despite the same orders of magnitude of peak water levels, the latter leads to a higher salinity increase. This is not reflected in the displacement of the 10 psu isohaline, but clearly in the maximum differences depicted in Fig. 8 a,b and 9 a. On the other hand, the scenario storm surge Storm $_{\mathrm{A}_{1 \mathrm{~B}} 1}$ with the highest surge throughout the estuary shows slightly less salt intrusion than storm Storm $_{\text {B1_1 }}$ with the second highest surge. To what degree the single components of the storm surges (peak water level, surge maximum and duration, wind speed) impact the salinity intrusion can therefore not be answered here due to the limited number of investigated storm surges and should be investigated.

\section{SUMMARY AND OUTLOOK}

The paper on hand presents an investigation of hydrodynamics and salinity during storm events in the Weser estuary, Germany. The work is part of a research project with the aim to assess possible impacts of anthropogenic climate change on the estuary by means of hydrodynamic modeling. Therefore, a model of the Weser estuary was set up based on an unstructured simulation tool for baroclinic cross-scale circulation (SELFE). By qualitative and quantitative analysis of simulated and observed time series at 
gauges throughout the estuary, it was shown here that the model performs well in reproducing the water levels and hydrodynamics of past storm surges.

To investigate the impacts of storm surges unhindered from other factors, a special approach was undertaken: For each simulated storm surge, an alternative no-storm simulation was carried out under the exact same set-up with the exception that surge and wind increase were removed from the boundary conditions for only the period of the storm event. The no-storm simulation was then compared to the storm simulation for analysis of the residua.

A series of storm surges was investigated in this study: The two past storm surges Britta (2006) and Tilo (2007) are the most intense storm surges of the recent past, but did not cause any losses due to the high protection level of the German coastline by dikes and flood barriers. To simulate more severe events with a realistic evolution, the study was complemented by three scenario based storm surges which were selected from long-term water level simulations of the North Sea in which possible impact of future anthropogenic climate change was taken into account. These events are named after the underlying projections Storm $\mathrm{C} 20 \_1_{1}$, Storm $\mathrm{B} 1 \_1_{1}$ and $\mathrm{Storm}_{\mathrm{A} 1 \mathrm{~B} \_1}$.

The results show peak high tides of approx. $5 \mathrm{mNN}$ for the three less strong storm events Britta, Tilo and Storm $\mathrm{C} 20 \_1_{1}$. The comparison of storm- and no-storm simulations revealed that the storms cause a displacement of the mixing zone of approx. $20 \mathrm{~km}$ upstream. The two strongest events, Storm $\mathrm{A}_{1 \mathrm{~B}} 1$ and Storm $_{\mathrm{B} 1_{-} 1}$, show peak high tides of almost $7 \mathrm{mNN}$ in the inner estuary. In case of Storm $\mathrm{A}_{\mathrm{B} \_}$, the increased surge with a maximum of over $5 \mathrm{~m}$ is intermittently present during a period of 8 days, resulting in a chain of three storm events with several increased tides each. Both events cause a displacement of the mixing zone of more than $30 \mathrm{~km}$ upstream.

The findings show a strong short-term impact of storms on hydrodynamics and salinity distribution in the estuary which might be increased by anthropogenic climate change. However, the two strongest events from the climate realizations presented here have comparatively high return values so that such impacts on salinity intrusion might be rare even in the case of the expected future climate change.

Other important forcing such as river runoff is currently investigated with respect to its impact on the salinity distribution. This factor strongly affects the seasonal variability of the mixing zone and thus has major implications on water management. These investigations are contributions toward an assessment of the impact of relevant forcing on the mixing zone in the Weser estuary together with their long-term changes.

\section{ACKNOWLEDGEMENTS}

This research is funded by the Ministry of Culture and Science of Lower Saxony, Germany.

\section{REFERENCES}

Bilgili, A., K. W. Smith, and D. R. Lyncha. 2006. BatTri: A two-dimensional bathymetry-based unstructured triangular grid generator for finite element circulation modeling, Computers \& Geosciences, 32, 632-642.

Gaslikova, L., I. Grabemann, and N. Groll. 2012. Changes in north sea storm surge conditions for four transient future climate realizations, Natural Hazards, , 1-18.

Grabemann, I., G. Krause, and G. Siedler. 1983. Langzeitliche Änderung des Salzgehaltes in der Unterweser, Deutsche Hydrographische Zeitschrift, 36, 61-77.

Jungclaus, J., N. Keenlyside, M. Botzet, H. Haak, J.-J. Luo, M. Latif, J. Marotzke, U. Mikolajewicz, and E. Roeckner. 2006. Ocean Circulation and Tropical Variability in the Coupled Model ECHAM5/MPI-OM, Journal of Climate - Special Section, 19, 3952-3972.

Niemeyer, H. D. and R. Kaiser. 2012. Evaluation alternativer Küstenschutzstrategien in Niedersachsen, Wasser und Abfall, 7-8, 21-26.

Rockel, B. and B. Geyer. 2008. The performance of the regional climate model CLM in different climate regions, based on the example of precipitation, Meterologische Zeitschrift, 17(4), 487-498.

Shewchuk, J. R.. 1996. Triangle: Engineering a 2D Quality Mesh Generator and Delaunay Triangulator, Applied Computational Geometry: Towards Geometric Engineering, 1148, 203-222.

Spekker, H.. 2008. Steuerung von Küstenschutzelementen an Tideflüssen als Grundlage für ein Hochwasser- und Risikomanagement. Ph. D. thesis, Universität Hannover.

Willmott, C. J.. 1981. On the validation of models, Physical Geography, 2, 184-194.

Zhang, Y. and A. M. Baptista. 2008. SELFE: A semi-implicit Eulerian-Lagrangian finite-element model for cross-scale ocean circulation, Ocean Modelling, 21, 71-96. 
Zhang, Y., R. C. Witter, and G. R. Priest. 2011. Tsunami-tide interaction in 1964 Prince William Sound tsunami, Ocean Modelling, 40, 246-259. 